\title{
La cultura emblemática jesuita en una Casa de Ejercicios Espirituales para señoras limeñas ${ }^{1}$
}

\section{Ricardo Estabridis Cardenas}
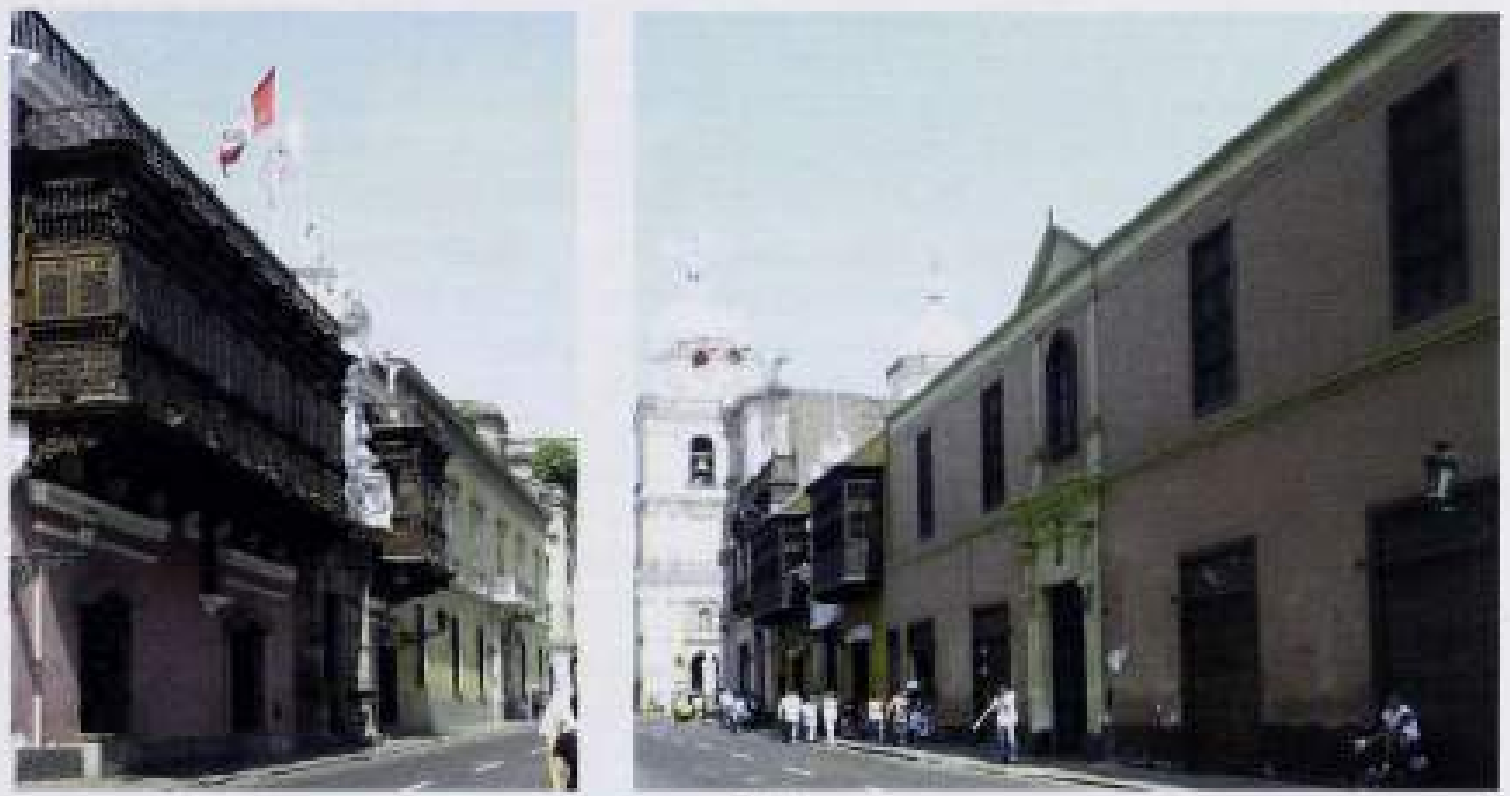

Fix 1

En el centro historico de Lima, a pocos pasos de la Iglesia de San Pedro en el jurón Ucayali. ubicamos la fachada de una casa del sigho XVIII, -la parte principal hoy convertida en un restaurante y el resto en otros locales comerciales- que contrasta en sus dos pisos y pórtico por la austeridad de su diseño con las fachadas de otras casonas limenas de la misma calle como la Casa Coyeneche y sobre todo la famosa de los marqueses de Torre Tagle. La sobriedad de su estilo va de acuerdo con los fines para los que fue edificada en 1752. para que sirviera como casa de ejercicios espirituales a las damas de la nobleza limena de entonces. Aunque ya por Resolución Suprema del Estado Peruano fue reconocida como patrimonio cultural de la Nación en el ano de 1972, según informes de los arquitectos del entonces Instituro Nacional de Cultura, lo poco que se conserva del edificio original es se fachada, en el interior una reja, la estructura de los muros en el amplio zaguan, un patio y una capilla muy intervenida. De su patrimonio artistico mueble no queda nada. (Fig. 1)

Esta edificación, a pesar de que hoy es el fantasma de una época. fue en el siglo XVII uno de los inmuebles mis representativos, no por sus dotes arcuitectonicas ni por ser la primera casa de ejercicios ignacianos para mujeres en Hispanoamerica e incluso en el mundo, según Vargas Ugarte (1941:70), sino por constituirse a través de su decoración pictórica en un monumento a la cultura emblemática difundida por los jestuitas en tierras americanas.

1 Articalo basado en la ponencia presentada en el Coloctio Internacional de Arte e Historias. En Memoria de fuana Gutierrez Haces $1948-2007$ ) reabizado en la ciudad de Mexico DF enl abril de 2008. 


\section{Fundación de la Casa de Ejercicios Espirituales para mujeres}

Casas de ejercicios para hombres si habian creado los jesuitas en Lima, la más importante fue la del Seminario de San Antonio Abad construida a inicios del siglo XVIL, en la granja conocida como la Chacarilla de San Bernardo, ubicada en el espacio que actualmente ocupa la Casona del Centro Cultural de la Universidad de San Marcos. Este monumento quedó destruido por el terremoto devastador de 1746 sin dejar rastro de las pinturas que lo decoraban. La Gaceta de Lima por los años sesenta de dicho siglo da cuenta de su reconstrucción ${ }^{2}$. Fste Seminario se cerro en 1769 y se creó en su lugar el Real Convictorio de San Carlos, después de la expulsión de los jesuitas. Antes de que ello ocurriera se dio la fundación en lima de la Casa de ejercicios para mujeres mencionada en 1752, gracias a dos personajes pilares de esta empresa, el jesuita cajamarquino Baltasar de Moncada (Vargas

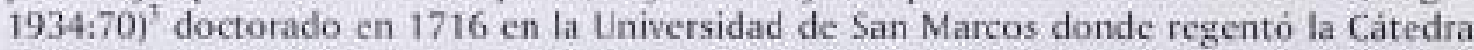
de Prima de Sagradas Controversias, y la dama dona María Fernández de Cordoba y Sande, Senora de Valdemoro, ilustre noble adinerada que enviudó de don Alonso Calderón de la Barca, de la orden de Calatrava, Corregidor del Cusco, sín descendencia y destinó mucho dinero para la adquisición del solar y su decoratión (Estabridis 2003:152).

El padre Moncada fue un jesuita a carta cabal que a lo largo de su existencia destacó no sólo por su catedra en la Real y Pontificia Lniversidad de San Marcos, sino por sus car. gos como Rector en los colegios jesuitas de diferentes ciudades del Reino del Perú. Pero ante todo ello primero fue un asceta, formado en el espiritu del libro de los Ejercicios Espirituales de San Ignacio de Loyola, texto que estudió, practicó y propagó en un estudio profundo publicado en Sevilla (Moncada 1754), Es laudable esta publicación por una parte porque en esta epoca no abundaban los comentarios a tan importante obra y por otra porque es uno de los que más aciertan a descifrarnos la clave de los Ejercicios y a desentrañar el artificio de su método.

La naciente casa de ejercicios de mujeres fue conocida como Casa de Ejercicios del Sagrado Corazón y desde sus inicios la acaudalada señora de Valdemoro la donó a los jesuitas, quedando ella como directora, superiora y portera y el Padre Moncada como director espiritual de los ejercicios. El monumento religioso fue bendecido a fines del mes de agosto de 1754 por el arzobispo de Lima don Antonio de Barnoeta y Ángel. Las noticias llegadas hasta Roma motivaron el especial agradecimiento a doña Maria por parte del General de la Compañia de Jesús el Padre Ignacio Visconti en laudatoria misiva (Vargas. 1947. $\left.\mathrm{N}^{0} 4450\right)^{5}$.

\section{Descripción de la Casa de Ejercicios para mujeres en el siglo XVIII}

De esta casa nos dejó Baltasar de Moncada una puntual descripción en la obra que se publicó en Sevilla (1757). Para entonces ya se había decorado con más de un centenar de pinturas desde la fachada, hasta los más recónditos ambientes, en el zaguán, el patio exterior y los dos interiores, coro y capilla que posee el edificio. La mayoria de las pinturas se enmarcan dentro de la tipologia considerada emblema, donde no solo se utiliza la imagen sino también la lite. ratura que explica o complementa el mensaje. Tomamos una definicion de Esteban Lorente:

"Emblema es una composicion simultaneamente pictórica y poètica, compuesta de un cuadrito con su mote acompanada de un epigrama de unos

2. Gaveta de Lima de 1762 a 1765. Apogeo de Anat. Edicion Facsinilar. Prol de Jose Durand Conte. Lima. 1982, , 198 .

3 Ruben Vargas Ugarte nos alcanza en este libro mucha información sobre su vide.

4 Ein ta Colección Níaza de Lima se cunserva su retrato ḱknde se lee en la leyenda de la sartela que foe funch. dota del monasterió de mxonjas nazarentas tefesianis. Hlo ocurric en 1730 y demuestra su equiritu devoto y caritativo ya desde aines anteriores.

5 Rubén Vargas Ugarte nos aicanza muchos documentes que sirven de base a los escritos sobre ta historia de esta casd. 
pocos versos; de ellos se extrae un aviso o lección humana de aplicación universal. El mote o lema va situado generalmente sobre el caradrito y no dentro de el, en pocas palabras da a conocer el asunto que trata el emblema. La pintura o cuadrito puede representar cualquier objeto, ser o composición. Al epigrama le conviene alguna forma poética sencilla; y ha de constar de dos partes, en la primera se describe la pintura y en la segunda se declara la moraleja. Lema y epigrama deben ir, preferentemente, en latin (1998:313)".

En una publicación sobre el tema del barroco peruano, editada por el Banco de Crédito del Peru, se hace una referencia a la descripción de la Casa de Ejercicios en el libro escrito por Moncada del ano de 1757 que fuera editado en Sevilla (Mujica 2002:250). Sin embargo, consideramos necesario anotar que dicha referencia fue parcial, ya que no se mencionó que hubo otra edición del libro un lustro despuès, en 1762, y que en dicha edición dada en Villagarcia, Pontevedra (Moncada 1762), se incluyeron más de medio centenar de pinturas de singular importancia para entender el mensaje completo. lo que nos ha permitido calificar a esta Casa, por la magnitud del programa, como el monumento a la cultura emblema. tica jesuita en el Peri virreinal.

Sin dejar de mencionar en forma sucinta lo ya descrito en obras de arte en la edición de Moncada de 1757, haremos mayor hincapié en las nuevas obras que se incluyeron en la edición de 1762, tratando de ilustrarnos en sus fuentes literarias asi como en grabados y en pinturas similares que aún subsisten en el Perú y en México, para recrear asi la literatura del hermano jesuita.

\section{La emblemática jestita usada en la Casa de Ejercicios para mujeres limeñas}

En el mundo cuitural de la contrarreforma de la Iglesia Católica, los jesuitas llevaron la ba. tuta en el campo de la orientación espiritual y para ello se valieron de la emblemática por ser un género propicio y adecuado, por su esencia gráfica y litetaria, al mensaje cristiano. Quedan como los más clasos y evidentes ejemplos de ello, en el siglo XVI, el proyecto de San Francisco de Borja el primero en componer unas meditaciones sobre los evangelios de los domingos del año (Borja, 1912), donde en su introducción se lee:

"...para hallar mayor facilidad en la meditación se pone una imagen que represente el misterio evangélico y asi, antes de comenzar la meditación, mirar la imagen y particularmente advertirá lo que en ella hay que advertir, para considerarlo mejor en la meditación y para sacar mayor provecho de ella, porque el oficio que hace la imagen es como dar gaisado el manjar que se ha de comer, de manera cque no queda sino comerlo............"

Proyecto que se haria realidad en el libro que vio la luz primero, el preparado por el P. Jerónimo Nadal $(1593)^{6}$. ilustrado con más de centenar y medio de imágenes grabadas por la familia Wierix, obra que llegó a América y se usó en la Casa que nos ocupa. (Fig.2) La misma familia de grabadores intervinieron en otra gran empresa temprana acorde con el

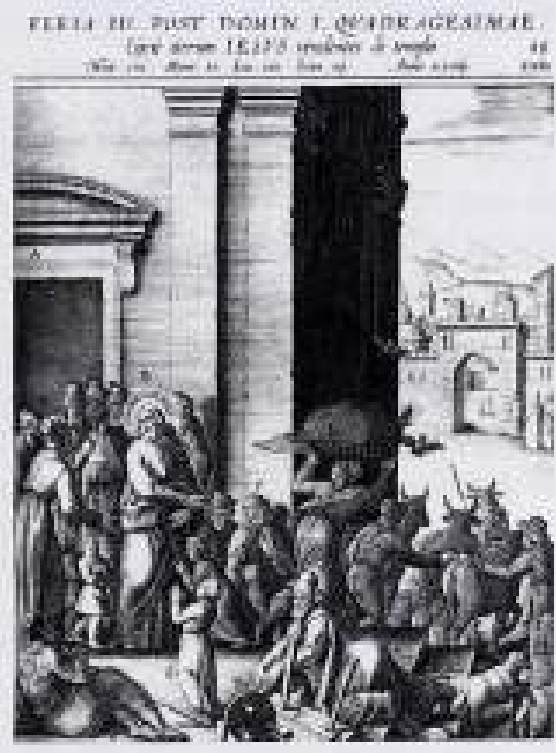

Fig. 2

6. A ba que 5tguieron muchas oxas edictones en 1595: 1596, 1606, 1607. etcetera. 


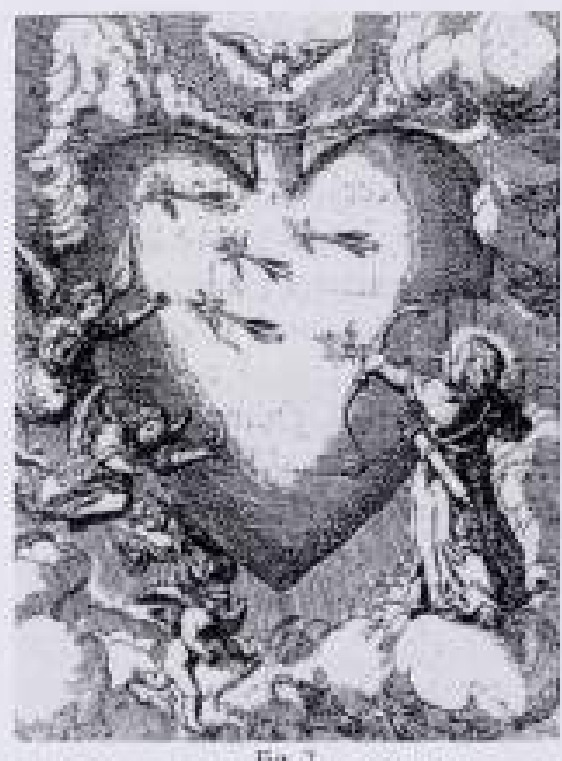

Fin, 3

simbolismo del corazón en relación a los ejercicios espirituales de San Ignacio. Esta serie integrada por dieciocho grabados realizados entre 1585-1586, fue muy difundida bajo el título: Cor Jesu Amanti Sacrum? estampas que también serian tomadas como modelos para las pinturas que decoraban el coro de esta Casa de Ejercicios limenta. (Fig. 3) La misma temática al. canzó gran éxito y en el siglo XVIl el grabador Boecio Adam Bolswert desarrolló otra serie con diferente composición que hemos comprobado se usó en el Perú en el Monasterio de Santa Catalina de Arequipa. (Estabridis 2010:151).

Por ulrimo, en esta breve referencia a algunas fuen. tes utilizadas en la casa limeña, no podemos dejar de mencionar al jesuita belga conocido como el Hermano Hugo", quien escribió en 1624 uno de los libros mas importantes de la contratreforma el Pia Desideria emblematis elegiis et affectibus SS. Patrum illustrada, obra famosa no sólo por su comentario mistico-literario, sino por los grabados que aparecen en cada capitulo. Los grabados de la primera edición latina de Amberes, 1624 fueron realizados por Boecio A. Bolswert. Hubo otras posteriores en Lyon (1625), Munich (1625). Paris (1645). Colonia (1673), Londres 11677), etc. La traducción castellana fue obra del jesuita Pedro de Salas Nalladolid, 1638 y 1558). bajo el titulo de Afectos divinos con emblemos sngrados (Sebastián 1981:65).

El Pia Desideria... fue el típico libro destinado a las almas contemplativas que seguían los ejercicios espirituales, dividido en tres partes dedicadas a los afectos del dolor y arrepentimiento (via purgativa o penitente), a los deseos de seguir a Cristo (via contemplativa o iluminativa) y a las ansias de unirse con Dios (via unitiva). El hermano Hugo siguió el esquema de las tres edades de la vida interior, en que aparece la vida espiritual como un proceso de crecimiento a lo largo de los tres periodos de la via mistica

Centraremos nuestra atención, a través de la descripción de Moncada en su libro de 1762. en algunos de los aspectos relacionados con las fuentes antes citadas empleadas por los jesuitas. Según la referida descripción la distribución de la fachada de la Casa de Ejercicios era de una gran puerta central, flanqueada por cuatro puertas de tiendis y sobre cada puer. ta una ventana y entre ventana y ventana tarjas con inscripciones que llamaban a reflexión sobre la Eternidad a todo aquel que pasaba. En el mismo centro, sobre la puerta principal la inscripción: "Casa de Ejercicios. Puerta de el Cielo". Al entrar al zaguán, con sus pinturas y textos cual emblemas, se nos recuerda en un marco de paisaje. la atraccion de los mortales hacia los bienes terrenales y la participación de jesuitas para que no caigan en el infierno. haciéndolos meditar sobre lo permanente y lo efimero.

Entrando en el patio, primero encontramos una veintena de emblemas que giran a un lado de la pared en torno al juicio del justo, la importancia de la confesión para estar en gracia, el alma guiada por un ángel en camino al cielo, entre los siete vicios capitales que tratan de impedir el paso. Las armas contra las tentaciones son la penitencia y la mortificación

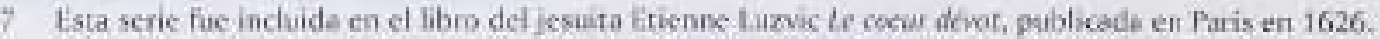

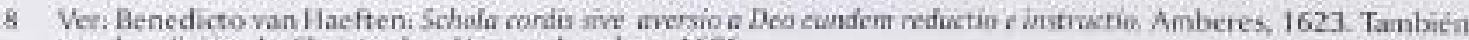
ver la edicion de Chrstophier Harvey, Loadres, 1636.

4 Es necesario-anotar que en todas lis ediciones consultadas del Pia Desiderio, se menciona que el autor es el Hermana Hugoy no se consigna el apellido Herimann, con el que ha sido poptlarizado por Santiago sebas! ian en todos sus escritos sobre la materia. 
representadas por cilicios, pan y agua. Todas las pinturas de este lado llevan arriba una representación de Cristo con la cruz a cuestas, seguido por penitentes igualmente con su cruz. En el lado izquierdo de este patio primero se destaca el mensaje opuesto, este gira en tomo a la muerte del pecador y la caida al infierno de los mundanos que siguen ef carro triunfal de los demonios y culmina en una puerta de rejas donde se lee: "Cárcel sin esperanzas".

\section{La capilla}

Moncada, ya en su primera edición de 1757, nos informa que en la testera que hace frente al zaguan existia una gran puerta de ingreso a la Sala que hacia las veces de Capilla, sobre la cual estaba pintada la Cueva de Manresa donde San Ignacio escribió los ejercicios espirituales que le dictó la Virgen Maria, rodeado de otros lienzos alusivos a santos que se convirtieron, se arrepintieron e hicieron penitencia, como San Pedro, San Pablo y San Antonio Abad. Sin embargo, la importancia de su ubicación està marcada por el tema central que da origen, motiva y justifica la existencia de esta casa y destaca en otras escenas la difusion que hacen de ellos jesuitas a otros jesuitas y también a seculares.

Es menester destacar que Moncada en la edición de 1757. al llegar a la gran sata que sirve de capilla nos dice: Adomaráse después de pinturas Sagradas. que sean al interior de los Ejercicios; porque hasta ahora no se ha podido". Un lustro después, para la edición de 1762 , ya se habian realizado y describe doce lienzos apaisados inspirados en algu-

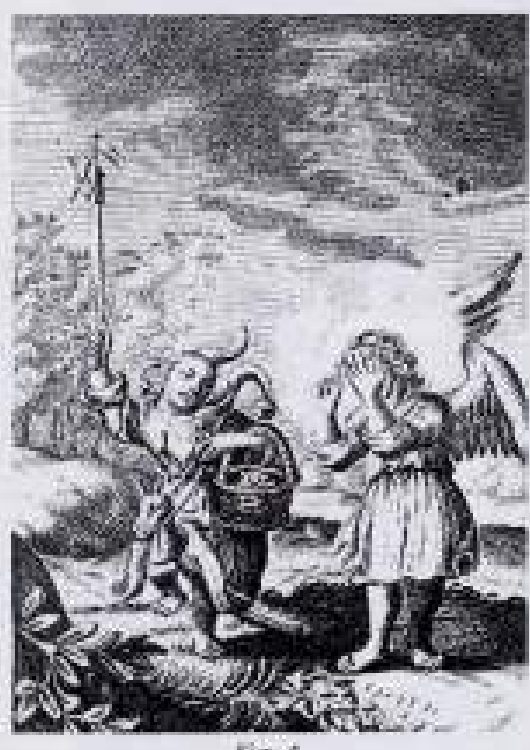

Fig. 4

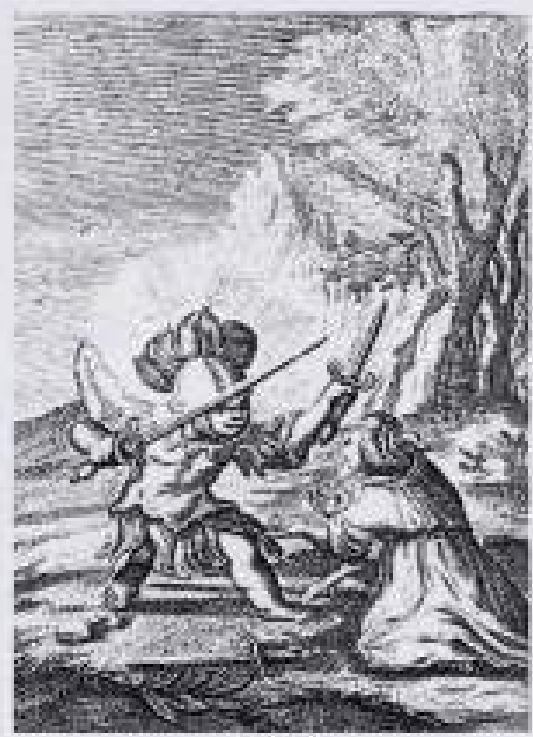

Fig. $4 a$ nos de los grabados que ilustran las diferentes vias en el libro Paia Desideria del Hermano Hugo.

El primer lienzo, inspirado en el segundo grabado de la vía purgativa o penitente donde el alma se representa jugando con un caballito de madera (Fig.4), está acompahado por el siguiente texto:

"Es posible, que una alma. / que crió Dios para el Cielo. / gaste su vida en locuras, / en galas, gustos, y juegos! / Es posible que esperando / bienes. 6 males eternos, / todo su cuidado sea / lo que dure breve tiempol/ 0 ceguedadl Ó ignorancia! / ó engañol 6 desacierto! / que cuando se reconozca/ serállanto sin remedio. / Ay de ti alma Christiana, / que miras aqueste lienzo, / si en ti no buelves, y enmiendas / tus locos pasados yerros".

El segundo, toma como fuente el primer grabado de la via purgativa o penitente en el que el alma es iluminada por el amor Divino con un lamparin y le muestra el camino. El tercero corresponde al sexto grabado de esta via purgativa o penitente donde el alma se rinde ante el Amor Divino armado a la romana (Fig.4a). El cuarto lienzo tiene por fuente de inspiracion el grabado trece de la vía purgativa o penitente donde el alma señala un reloj solar y liora ante Amor Divino por lo fugaz de la vida. En la quinta pintura se toma como modelo el segundo grabado del libro segundo del Hermano Hugo, correspondiente a la via iluminativa o 

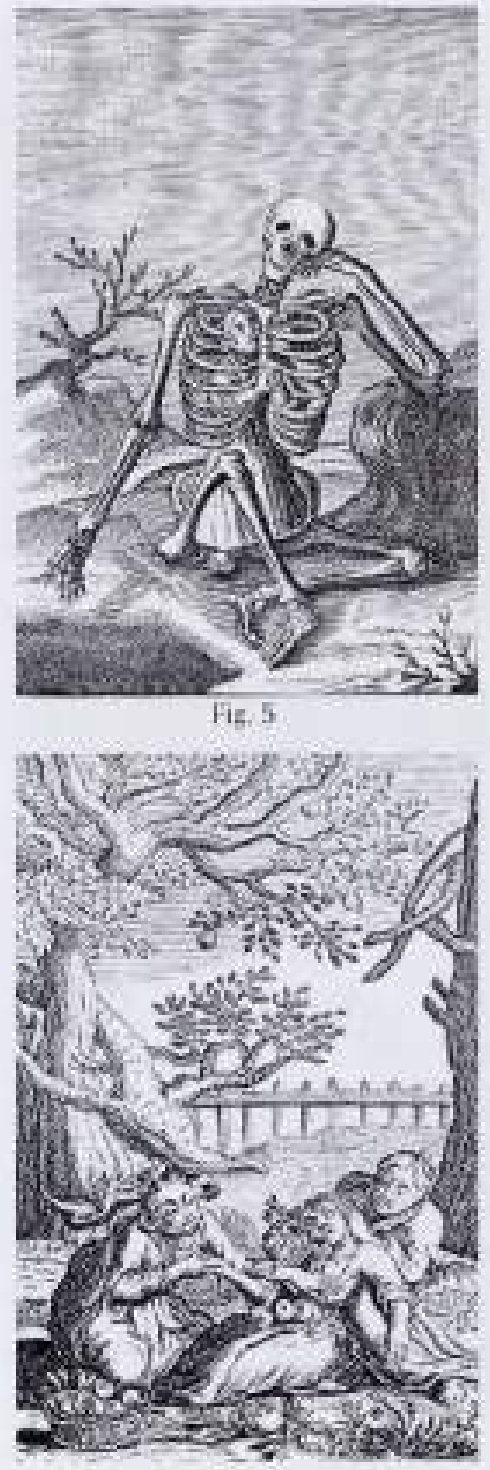

Fin 6

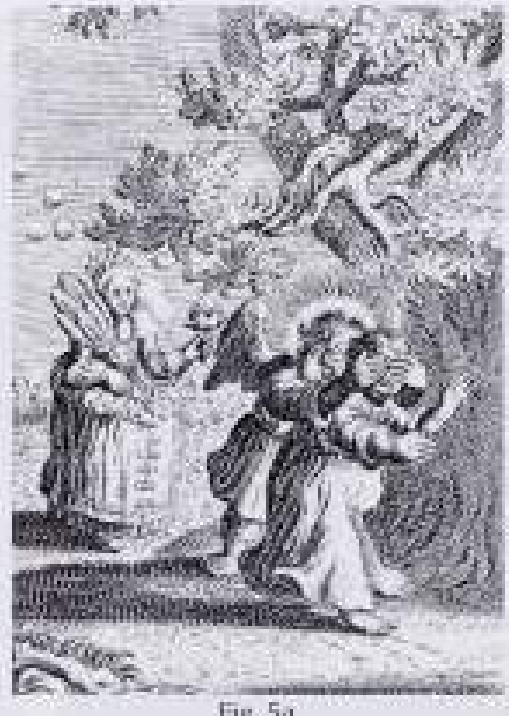

Fig. 5 a

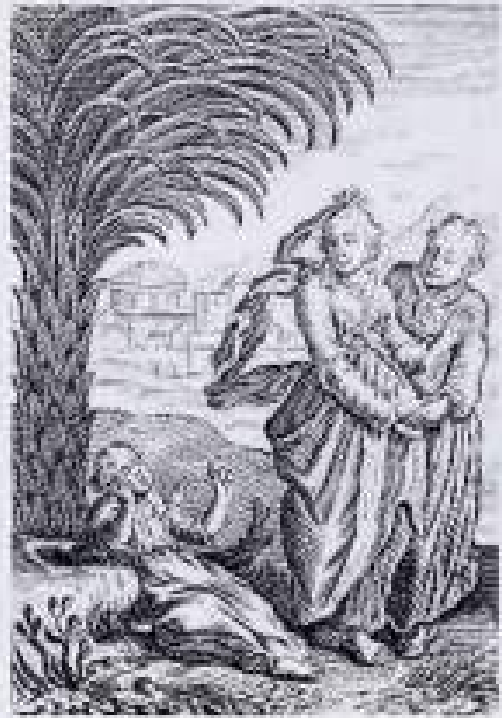

Fill fa

contemplativa, donde el alma camina en un laberinto asida al cordón que desde el cielo le manda el Amor Divino. La sexta pintura, donde se representa al alma presa dentro de un esqueleto, tie. ne por fuente el octavo grabado de la Via Unitiva. (Fig.5) En el sétimo lienzo vuelve a la via iluminativa o contemplativa ya que se toma como modelo el grabado $X$ de esta vía. donde se ve al alma que busca al Amor Divino en su lecho y no lo encuen tra porque está durmiendo en el suelo sobre una cruz. El octavo muestra al Amor Divino cubriendo los ojos al alma para que no vea a lis vanidad. inspirado cn el grabado $V$ de la Via Contemplativa o iluminativa, (Fig.5a) En el lienzo noveno Moncada describe al alma inclina. da ante el Amor Divino como juez en una mesa escribiendo en un libro. Al parecer corresponde al grabado $X$ de la Via Purgativa o Penitente

donde además se incluye al bado del Alma a la alegoria de la Justicia.

Los tres últimos lienzos están inspirados en grabados de la Via Unitiva. El décimo muestra al alma en una jaula, de donde se apresta a sacarla con una llave el Amor Divino, curres. pondiente al grabado $X$. En el decimoprimero aparece en un marco de paisaje el Alma desmayada en el campo, mientras dos mujeres la confortan con flores y con manzanas, inspirado ell el grabado II de esta vía. (Fig.6) El decimosegundo y último responde a la fuente del grabado I de esta vía, en el que el Alma figura desfallecida con las saetas de amor en el corazōn, mientras se dirige a dos mujeres que pasan. (Fig.6a)

Al pie de este último lienzo estas coplas:

"O amorl amor insaciable, / que no sabes decir, basta: pues tu llama trae deseos. / tus deseos traen mas llamas. / Sin duda alguna eres Dios, / en quien con union mui rara, / los gozos, y los deseos / hacen perpetua la alianza. /Mas enciendes mis deseos / mientras mas mi pecho abrasas, / da posesion, y recibe/ansias, ansias, y mas ansias. / Agta, que me abraso. Cielos, que me abrasa el fuegua, agua: / mas si el agua enciende el fuego. No hai remedio: que arda, que arda". 
El uso de los grabados relacionados con las vias para alcanzar la perfección hasta la unión con Dios se encuentra demostrado en diferentes lugares de Hispanoamérica. En el Perú, en el Monasterio de Santa Catalina de Arecuipa existe una serie completa de lienzos anónimos inspirados en el Pia Desideria det Hermano Hugo que decora el claustro de los Naranjos (Estabridis 2010). como ejemplo se muestra aquí el que corresponde al primero de la Via Unitiva. (Fig.7)

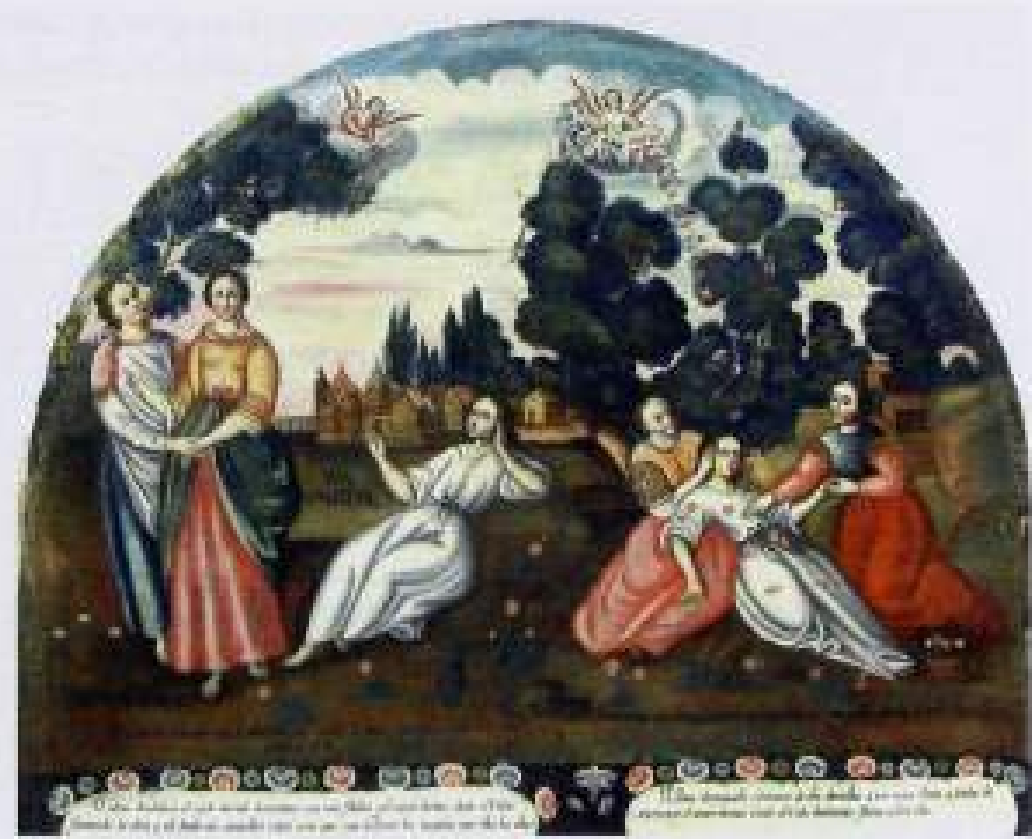

fig 7

En esta misma Sala se

incluyeron también nuevos lienzos entre los que es menester destacar dos que representaban a los árboles de la vida y de la muerte, los que inchuso fueron dibujados en la edición de 1762. Sus caracteristicas responden a dos lienzos que se conservan en la iglesia de San Pedro de Lima, aunque son de un formato mayor. En el árbol de la vida (Fig.8) vemos por medio de leyendas y figuras el proceso de crecimiento del alma hacia la perfección a través de la penitencia y la mortificación. Todo remata en las llamas que representan el amor a Dios a través de la santidad. Corona el árbol la Santisima Trindad. Fi árbol de la muerte (Fig.9) sigue el mismo esquema de figuras y leyendas pero en él se destacan las malas raices con viboras y animales demoniacos. Aquí el remate de su copa muestra el esqueleto de la muerte guadana en mano (Mujica 2002:256)" .

No falta en la capilla un lienzo inspirado en el grabado de Jerónimo Wierix al que recurrieron muchos pintores en diferentes partes de Hispanoamerica para representar la hora de la muerte. Fn d se indu. ye un ârbol que es cortado por la figura de la muerte mientras un de. monio tira de el. Al lado Cristo a punto de tocar una campana que pende del tronco, mientras la Virgen tata de detener

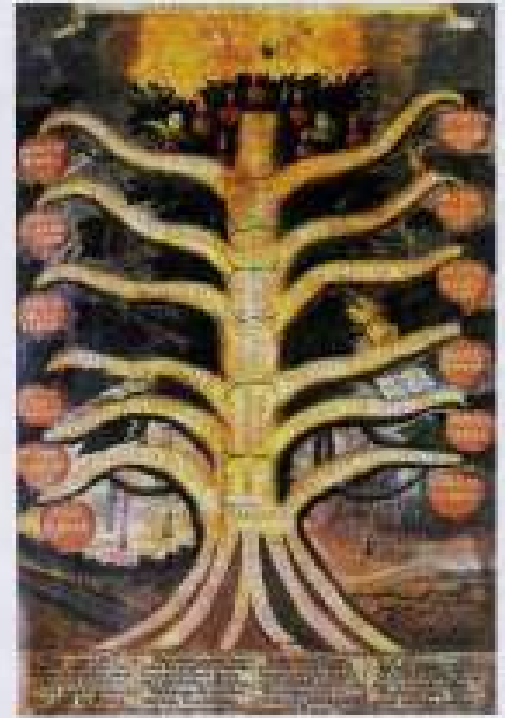

Fig. 8

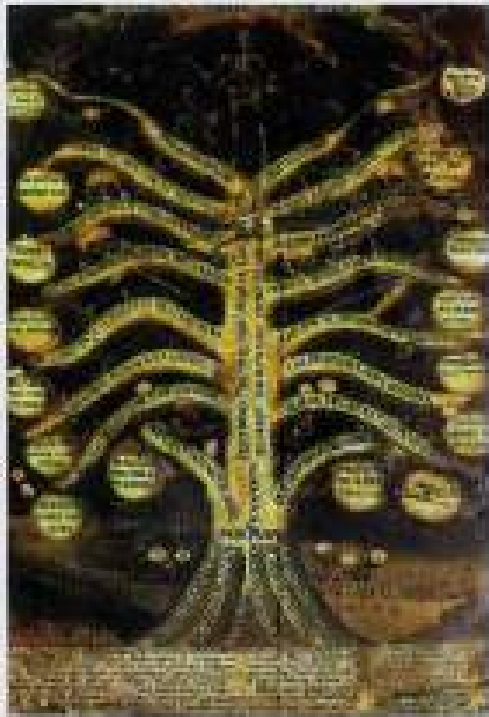

Fig, 9

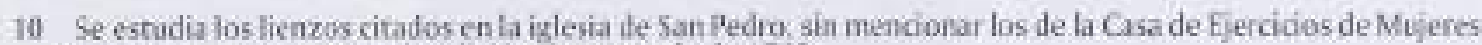
que figuran dilajjatos en la edicisis de Moincada de 1762. 


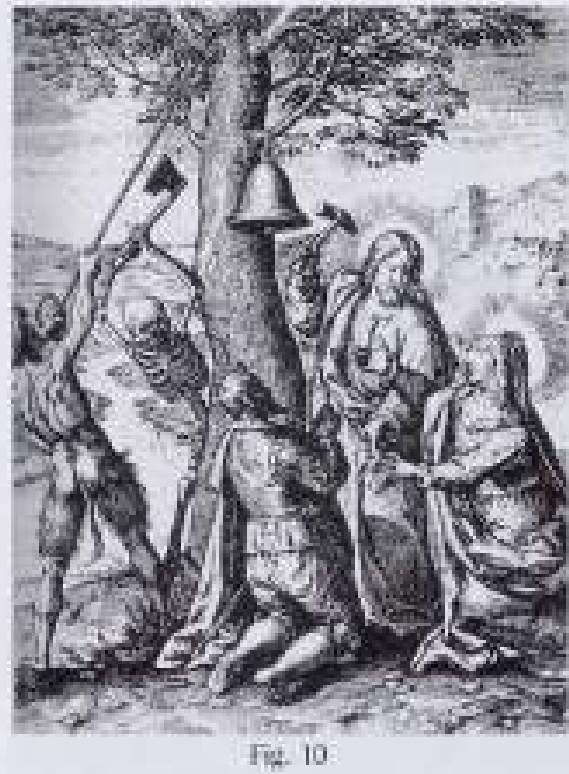

su mano para que no marque la hora final del personaje a los pies del árbol, quien se vale de su patrocinio. (Fig. 10)

La sala principal que sirve de capilla está dividida del oratorio por una reja que la separa del coro bajo sobre la que se agregaron varios lienzos según la segunda edición del libro de Moncada. Entre cllos podemos resaltar uno de gran formato con la Virgen de patrocinio protegiendo con su manto a jesuitas y otros santos que han hecho los Ejercicios en su vida. Asimismo, otro de igual tamaño con Cristo entregándole a San Ignacio el estandarte de su Compania y la Virgen el libro de los Ejercicios. Igualmente, junto a la reja que divide la Sala de el Oratorio, un lienzo muy grande, en el que se observa un monte dividido en dos puntas, como el Parnaso; en una esta Cristo derramando sangre de su costado, y en la otra está la Virgen vertiendo leche de sus pechos en el mismo lado, donde las almas se recrean en forma de avecillas. Lo acompanan estos versos:

-En este Sacro Parnaso, / monte de cumbre partida, / preside Apolo Jesús, y por Minerva Maria. / Con el nectar de sus pechos/Maria Azucena cria; / y con su Sangre Jesús, / rosas sin numero anima. / Cuanto riegan esta agua, / tanto de flores matizan; / flores que alegran los Ciclos, / flores, que la ticra admira./ De el raudal de sus corrientes, bella fuente se origina, la Castalia fuente, en que i candidos Cisnes habitan.

Ven á beber de estas aguas, i pecador, que son de vida, / y deja las muertas, que / el Mundo faliz te brinda. / Ven, y bebe, que son dulces, / son suaves, no fastidian; / y el pece ingrato destruien / de las culpas enemigas. Ven, y bebe, pues los Cisnes, / que en esta fuente se crian, / en la vida. y en la muerte, / dulcisimamente trinan. / Bebe, pues, de estos cristales, / si feliz, eterna vida / quieres lograr en el Cielo. / con Jesús, y con Maria",

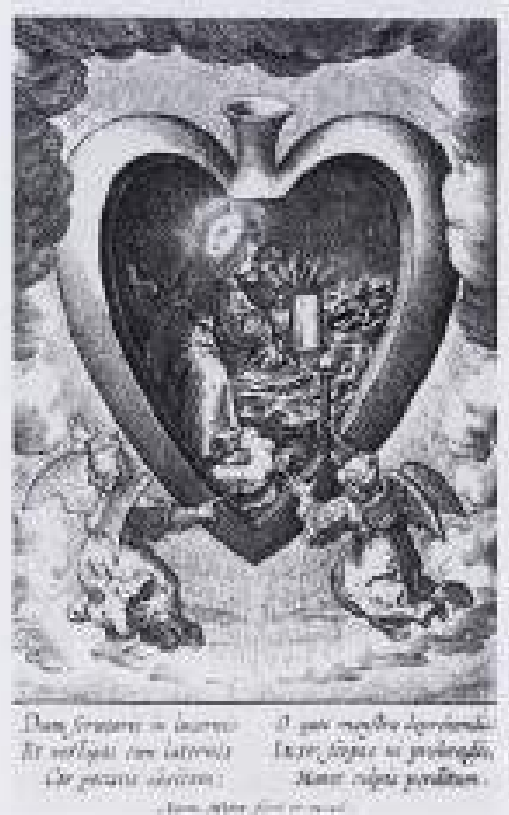

Fig. 11

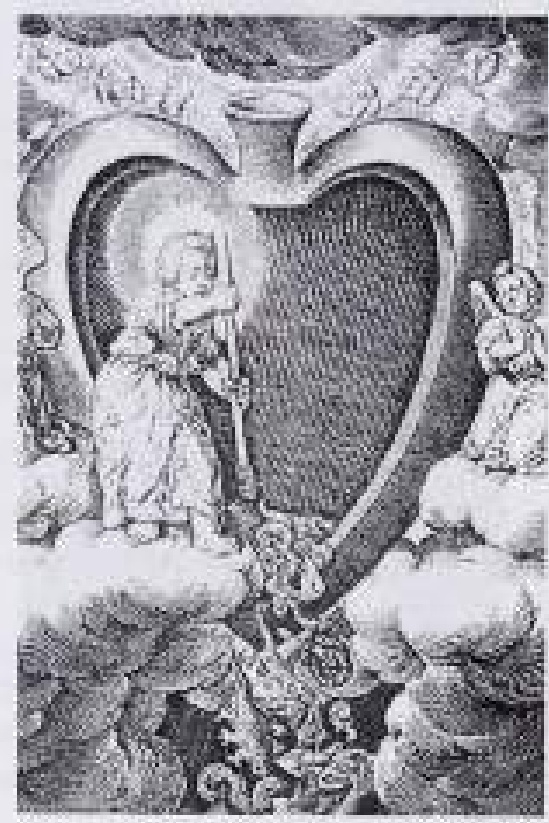

Fis. 11 a

\section{El coro bajo}

En el ambiente correspondiente al coro bajo se ubico. ya desde la inauguración de la Casa, la serie del corazón popularizada por los jesuitas en base a los dieciocho grabados encargados a Antón Wierix: El corazon humano conquistado por el Niño Jestis, realizados entre $1585-1586 \mathrm{y}$ que perduraron a lo largo de los siglos en varias ediciones. Responden a las siguientes denominaciones: 
- Corazón sostenido por San Ignacio y San Francisco Javier

- Corazón atado con redes por mundo demonio y came y liberado por el Niño lesús y el angel de la guarda.

- Niño tocando la puerta del corazon.

- Jesús con linterna ve demonios dentro del corazón. (Fig.11)

- lesús barriendo el corazón de demonios. (Fig, lla)

- Jesús de sus llagas derrama siete arroyos de sangre que aluden a los siete sacramentos.

- Jesús con plumero limpiando los pecados veniales del corazón.

- Jesús pintando en el corazón, muerte, infierno, juicio y gloria.

- Jesís introduce elementos de su pasión en el corazón.

- Jesús lee libro dentro del corazón.

- Jesis toca en arpa en el corazón.

- Jesús cantando con un papel de alfa.

- Jesús en el corazón sentado en truno con corona y cetro.

- Niño en corazón rodeado de rosas y flores.

- Niño fuera del corazón lanzándole saetas de fuego de amor.

- Niño duerme en corazón en medio de termpestades.

- Niño al centro del corazón en llamas y resplandores.

- Corazón llevado en palmas por ángeles y coronado por el Niño en el cielo.

Existe una serie de pintu. ras en el Convento de los Descalzos de Lima en muy mal estado (Fig.12) que está relacionada intimamente con la serie que nos ocupa y se conservan otros ejemplos similares en México (Morera 2000:121). (Fig.13)

\section{La sacristia}

La sacristia de la Casa de Ejercicios que tratamos se ubica frente al coro bajo y en ella estaban colgados diez lienzos de los cuales cada dia se ponía uno encima de la puerta de ingreso a este ambiente, para que lo tengan a la vista las se ñoras que están en el coro y les sirva para la meditación. Ellos variaban conforme a los puntos que trataba el sacerdote en su prédica y respondian a las siguientes caracteristicas:

Primer lienzo: Del fin para el que fuimos creados

En este se ve sobre un monte el Paraiso, y en el a Dios con Adan y Eva. Al pie de este monte está una puerta por
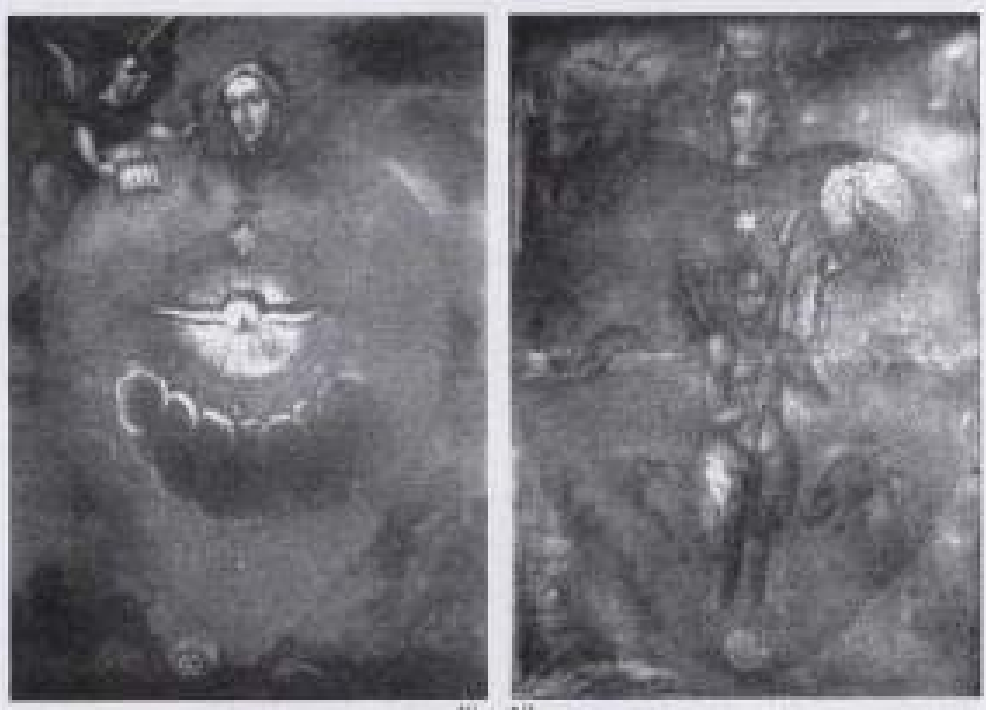

Fif: 12

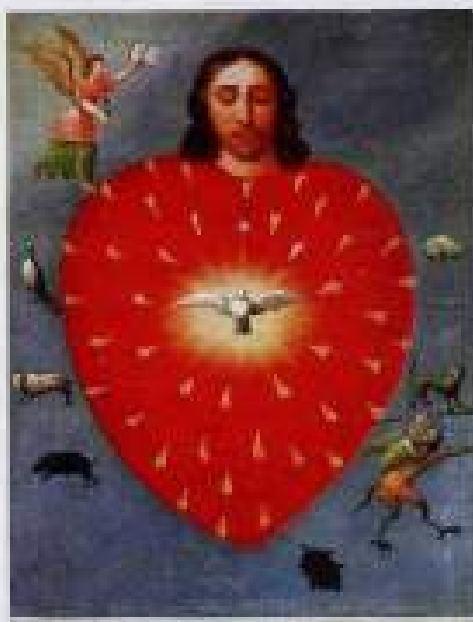

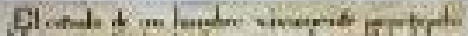

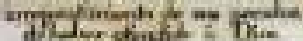

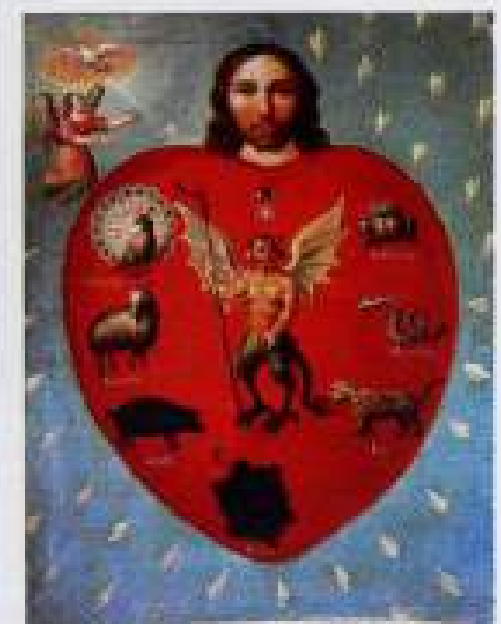

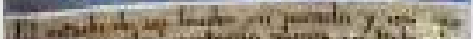

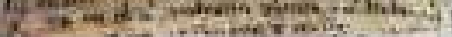


donde salen sus hijos; unos tiran para la derecha, entre espinas, penitencias y por ella suben a la puerta del Gelo; otros van hacia a la siniestra, entre flores y citaras y se precipitan al infiemo. En medio del lienzo está un hombre de cuerpo entero, como dudoso de lo que ha de hacer, y a un lado un angel con una balanza que le dice: escoge.

\section{El segundo lienzo: El pecado mortal.}

En el se mira la caida de los ángeles rebeldes y el pecado de Adán, y a un lado una serpiente grande de siete cabezas.

\section{Tereer lienzo: La multitud de los pecados,}

En el se ve a un hombre con cadenas en pies y manos, cabalgado por el demonio y rodeado por los vicios. Mientras un ángel le levanta el velo que cubre sus ojos para que vea el infierno en que camina.

\section{Guarto lienzo: La muerte.}

Enmarcado dentro de la tipología de los jeroglificos del pintor español Valdés Leal, vemos en la parte superior del lienzo a la muerte con su guadana, pisando a todo tipo de hombres y dignidades, mientras en la mitad inferior se representan a dos moribundos, uno acompanado de angeles y el otro asistido de demonios.

\section{Quinto lienzo: Del Juicio Universal.}

En él están representados todos lo horrores de este dia, trompetas que llaman, muertos que resucitan, juez que sentencia, ángeles que separan los buenos para el cielo y los malos para el infierno.

\section{Sexto lienzo: Del Infierno.}

En el se miran representadas entre llamas la diversidad de penas a la multitud de condenados.

\section{Lienzo séptimo: De la Eternidad.}

En éste se miran en la parte superior la gloria, con Dios, ângeles y santos y en la parte inferior et infierno con los demonios y condenados. En medio esta el simbolo de la eternidad representada por la culebra que se muerde la cola. Encima de éste la muerte con un reloj de arena, que ya se acaba.

\section{Lienzo octavo: Es de la conquista del Reino de Cristo.}

Fn este se mira copiada una estampa de este asunto, que tiene en el Libro de sus Ejercicias el 1 . Zacarias Trinkelio. (Moncada 1762)) En ella se representa en la cumbre de una escalinata a Cristo en su trono, sentado con corona de espinas en la cabeza y cruz grande en las manos. A los lados varios angeles con los instrumentos de la Pasión, y en la zona inferior a varios cristianos que toman sus cruces para subir las gradas hacia Cristo.

\section{Lienzo noveno: De las dos banderas.}

En este se miran en lo alto dos banderas grandes, una blanca, en que se ven instrumentos de penitencia y otra roja con placeres mundanos. Al lado de la bandera blanca. Cristo de cuerpo entero, con cruz en las manos, acompañado de sus apóstoles y al lado opuesto Lucifer en una cátedra alta de fuego, con su tridente en la mano, acompanado de muchos demonios.

\section{Lienzo décimo: Que sirve cuando se da la meditaciōn de la Pasión, y tambièn cuando se da la meditación del amor de Dios.}

En él se mira un altar con una cruz grande, que coge lo más del lienzo. A los lados todos los instrumentos de la Pasion. Sobre la ara del altar unas llamas de fuego y entre estas un cordero atado derramando su sangre.

\section{El segundo patio}

Para la decoración del segundo patio, descrita en gran parte en la edición de 1757 , los pintores se centraron en temas relacionados con santos y santas ermitañas que practicaron la penitencia y la meditación. Posteriormente, durante los cinco anos que mediaron hasta 
la edición de 1762, se agregaron una serie de catorce lienzos en torno a representación de bovedas y cadaveres de dignidades reales y eclesiásticas, asi como de personajes comunes de diferentes razas e infante, todos ellos acompañados por tarjas con versos.

A un lado del patio se ve en primer lugat una bóveda en la que se representó el cadáver de un Papa en su féretro, con todas las insignias pontificales, $y$ a los lados de la bóveda dos tarjas con estas coplas:

"En esto paran del mundo, / las dignidades mas altas: / las Pirpuras, las Coronas, / las Mitras, y las Tiaras. / O que poco tiempo duran sus luces, sus alabanzas: / y en eterno olvido quedan, /cuando en la muerte se apagan".

Así como en esta representación vemos seguidas la de los cadaveres de un cardenal, de una reina, el de una señora en particular composición, ya que sólo la mitad de su cuerpo es esqueleto, muy similar a la que hiciera en la siguiente centuria el pintor Tomas Mondragón en la Profesa en 1856 (Fig. 14). Continua con el cadaver de una mujer negra y otros dos con esqueletos y varios despojos de huesos.

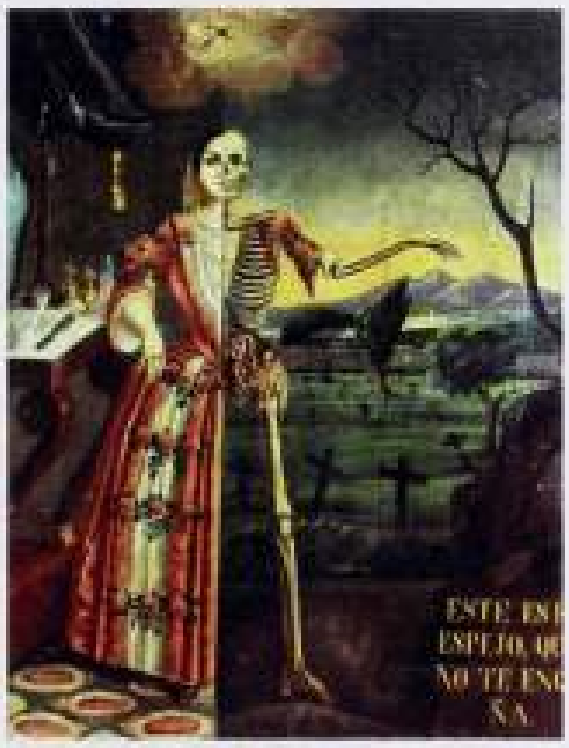

Hig. 14

Al otro lado de este patio, frente a la boveda del Papa se puso la pintura del cadaver de una niña, seguida por la de un obispo, frente a la del cardenal, igualmente la de un rey al frente de la reina. A ellos siguen las bovvedas de los cadaveres de una mulata y de una india. Acompanan a esta úitima los versos que reproducimos a continuación:

"India fui, mas ya no soi. / porque mi origen primero, / como el de todos los hombres / ya se acabó con el tiempo. / Solo mis obras me quedan / cuando en tierra me convierto: / las malas para el castigo, / y las buenas para el premio".

Las dos ùltimas bóvedas de este costado, contienen igualmente esqueletos y osarios. En México, en el Museo de Toluca, existe una pira que puede servirnos de referencia porque responde a similares caracteristicas y de seguro contó con la misma fuente gráfica. (Fig.15)

En este segundo patio se ubicaron los aposentos de las ejercitantes y se pintaron desde los inicios, en el umbral de cada puerta el símbolo de la Eternidad de Horapolo y en los interiores escenas de la pasión de Crísto, de seguro basadas en los grabados de la Historia de las imágenes evangélicas del P. Nadal ya que, según el P. Moncada, cada una iba

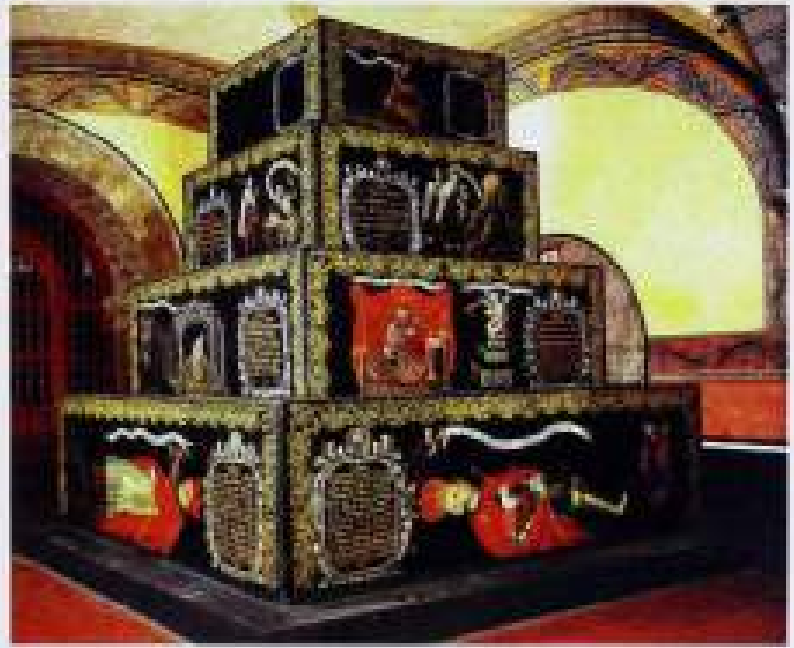

Fig. 15 acompanada de letras iniciales y leyendas. Un buen ejemplo de ello lo encontramos en el convento de Santa Teresa de Ayacucho en el Peri y en la decoración del convento de Atotonilco en México (Santiago 2004)".

11 Eprograma iconografico desarrollado es muy semejante al de la Casa de Ljercicios de lima. 


\section{La cocina}

La cocina, dispuesta en el tercer patio de la casa igualmente fue decorada con pinturas y cartelas mnemotécnicas, en este caso unas alusivas al ayuno de santos que se niegan a los manjares o a escenas de vida de santos desarrolladas en este ambiente, como las de Mariana de Jesús y San Diego. Destaca el pan de Dios en la representación de Moisés y el maná en el desierto. No falta la alusión a los tres fuegos, el del infiemo en un pozo profundo, el del purgatorio con ánimas y el del Amor Divino, con un corazón resplandeciente.

\section{La cárcel sin esperanzas}

Existía una parte de la Casa de Ejercicios conocida como la Carcel sin esperanza y era un largo callejón que corria desde el primer al tercer patio y en él estaban concentradas las escenas alusivas a los pecados, la condenación y las penas del infiemo, pintadas en tal forma que el mismo P. Moncada nos dice:

“...todo este callejón causa tan grande horror y espanto que muchas personas al entrar a mirarlo se bajan en copiosas y amargas lägrimas; otras al entrar en él, se han llenado de tanto horror, que salen corriendo, sin poder mirarlo. Pero en el dia que se da en los Ejercicios la Meditación del infierno se pide a las que hacen ejercicios que vayan por un rato a este callejón....

E objetivo es evidente: que surja en ellas la necesidad de ser almas cristianas. y a través de los ejercicios espirituales ser alumbradas de la fe católica, para no caer en tan terribles tormentos. En conclusión, aún en la segunda mitad del siglo XVIII, los jesuitas mantenian con fuerza el propósito desengañador de las banalidades, en el marco de una sugestiva espiritualidad barroca a través del arte y la literatura".

\section{El epilogo}

Ej jesuita historiador Rubén Vargas Ugarte nos alcanza en sus escritos información sobre lo que ocurrió con la expulsión de los jesuitas y como gracias a los reclamos de la fundadora de la Casa de Ejercicios ante el Virrey Amat, se evitó su enajenación y se logró la continuación de su funcionamiento (Vargas 1965:76). Asimismo por él sabemos que hasta los anos sesenta del siglo pasado funcionaba como asilo de ancianas o mujeres pobres. De su riquisimo patrimonio ya por entonces apenas menciona que existia un gran lienzo alegórico de los ejercicios y un cristo en escultura que perteneció a la iglesia de la Companía del puerto del Callao (Vargas 1963:101). 


\section{Bibliografia}

Borja, San Francisco de

1912 El Evangelio medtirado. Impreso en Madrid por el P. Federico Cervós.

\section{Estabridis, Ricardo}

2003 El retrato del siglo XVIII en Lima como simbolo de poder. En El Barroco Peruoco 2. Lima. Edit. Banco de Crédito del Peru: 135-171.

2010 Arte y Vida Misticat El Alma y el Amor Divino en la pintura virreinal. En Revisto del Museo Nacional T. L. Lima. Ministerio de Culture: 129-155.

\section{Esteban Loreute, Juan Francisco}

1998 Tratado de Feonografic. Madrid. Edit. istmo.

\section{Haeften, Benedicto van}

1623 Schola cordis sive aversio a Den eandem reductio e instructio, Amberes.

\section{Hugo. Hermano}

1624 Pia Desideria emblemaris plegiis et affectious SS, Putrum illastroda. Amberes.

\section{Luzvic, Etienne}

1626 Le coeur deqos, Paris.

\section{Moncada, Baltasar de}

1754 Arte de la Santidad explicado o declaración de la harmonia, metodo y artificao que contiene el libro original de los ejerricios que escribió en Manresa S. Ignacio de Loyula. Su autor el R.R. Baltasar de Moncada de la Compania de Jesurs, Pravincial de Quito y de la Proviacia del fera. Catedrático de Prima de Controversias en la Real Liniversidad de San Marcos de Lima. Con licencia. En Sevilla. En da tmprenta de Joseph Padrino. Mercader de libros en calle Genova.

1757 Descripciōn de la casa fabricada en Lima, corte def Peril, pera que las Senoras ilustres de elika y las demas mujeres devolas $y$ ins que deseen servir a Dios Nuestro Senor, pueden terter en total reliro y con toda abstraccioin y dinección necesario. los ejercicios de San Ignacio de Loyola. Consagrase a María Senora Nuestra, Athora de dichns ejercicios y la ofrece a las Sentoras ilustres de lima pora aumento de sur devorion el Doctor Balthasas de Moricada. Con licencia, En Sevilla por Joseph Padrino, Impresor y Mercader de libros, en calle Génoya.
1762 Descripcioñ de ia casa fabricado en Lima, corte del Perui, para que fas Señoras ilustres de elle y las demas mujeres devotas y las que deseen servir a Dios Nuestro Senot, pueden tereer en total retizo y can toda abstracción y direccion necesario, los ejercicios de San Ignacio de Layola. Consagrase a Maria Sellom Nuestra, Ahoura de dichos ejercicios $y$ Ia ofrece a las Semigras duesturs de Lima para atunento de zu devocián el Doctor Bolthasor de Moncado. En Villagarcia. En la imprenta del Seminario.

\section{Morera, Jaime}

2000 La Eucaristia. Simbolo y sintesis del dogma católico. En Parabola Novahispana. Cristo en el Arte Virreinal, Mexico. Fondo Cultural Banamex: $121-146$.

Mujica, Ramón

2002 El arte y los sermones. En El Barmce Peruano. Lima. Edit, Banco de Crédito del Perui. 219.313.

\section{Nadal, Jerónimo}

1593 Evangelicae historiae inagines, .... Antuerpiac.

Salas, Pedro de

1638 Afectos divinos con emblenas sagrados. valladolid.

\section{Santiago Silva, Jose de}

2004 Afotoniloo, Alfaro y Porissange. México. Colección Arquitectura de la Fe, Edit. 1 a Rana.

\section{Sebastiánt, Santiago}

1981 Contrarreforma y barroco. Madnd. Edit. Alianza forma.

\section{Vargas Ugarte, Rubén}

1934 lesuitas hnos, desrerrados a Italia. Lima.

1941 Los lesuitas del Perui. Lima.

1947 Maniscntos perzanos en les bibilotrcas y anfinos de Europa $y$ America. Tomo V. N 4450. Buenos Aires:

1965 Historia de ia Companian de Jesuis ent el Perii. Tomo IV (1703-1767). Burgos. 